\title{
Medial elbow injury in young throwing athletes
}

\author{
Bonnie Gregory \\ John Nyland
}

Division of Sports Medicine University of Louisville, Louisville, KY

\author{
Corresponding author: \\ John Nyland \\ Division of Sports Medicine \\ University of Louisville \\ 550 S. Jackson St., First Floor ACB \\ Louisville, KY 40202 \\ e-mail: john.nyland@louisville.edu
}

\section{Summary}

This report reviews the anatomy, overhead throwing biomechanics, injury mechanism and incidence, physical examination and diagnosis, diagnostic imaging and conservative treatment of medial elbow injuries in young throwing athletes. Based on the information a clinical management decision-making algorithm is presented.

KEY WORDS: elbow, injury, ligament, throwing.

\section{Introduction}

An estimated 30 million children participate in some form of organized sport in the United States ${ }^{1}$. As that number increases each year, the incidence and significance of overuse injury becomes more and more evident ${ }^{2,3}$. Over the last several decades, there has been a noted rise in the frequency of serious medial elbow injuries in young, overhead-throwing athletes. Several sports in particular show a high incidence of medial elbow injury-baseball, javelin, water polo, tennis, handball, and gymnastics-based on stress placed on the elbow during throwing, power gripping (as in racquet sports), or weight bearing (gymnastics). Often difficult to diagnose in the skeletally immature athlete, these injuries often require intervention by medical and rehabilitation specialists. Though most studies in this area have been related to baseball pitchers, a similar clinical decision-making and diagnostic process can be applied to young athletes involved in other sports. The incidence of elbow pain in young baseball players is between $20-30 \%$ for $8-12$ year olds, approximately $45 \%$ for $13-14$ year olds, and over $50 \%$ for high school, college, and professional athletes ${ }^{4-7}$.

Despite considerable research focused on overhead throwing biomechanics, risk factors for elbow injury, and use of innovative diagnostic modalities such as ultrasound, medial elbow injuries remain problematic for young athletes and a challenge for the physicians who take care of them. A recent study revealed that $31 \%$ of baseball coaches, $28 \%$ of players, and $25 \%$ of parents do not believe that pitch count is a risk factor for elbow injury. A similar percentage of baseball coaches, players, and parents do not believe that pitch type is related to elbow injury. Most surprising, $30 \%$ of baseball coaches, $37 \%$ of parents, $51 \%$ of high school athletes, and $26 \%$ of collegiate athletes also believed that "Tommy John surgery" or medial collateral ligament (MCL) reconstruction should be performed prophylactically on athletes without elbow injury to improve performance ${ }^{8}$. These misconceptions continue despite recommendations by the United States of America (USA) Baseball Medical and Safety Advisory Committee that encourages pitch count limitations, avoidance of several pitch types, and noparticipation in multiple leagues and/or yearround baseball ${ }^{9}$.

The role of the physician as an advocate for these young athletes cannot be overstated. In addition to diagnosis and treatment, the clinician must identify risk factors for medial elbow injury and aid in their prevention, particularly in the young overhead throwing athletic population. The purpose of this report is to review the anatomy, overhead throwing biomechanics, incidence, pathology of injury, physical examination and diagnosis, diagnostic imaging and conservative treatment of medial elbow injuries in young athletes with special attention paid to overhead throwers. Based on this information a clinical management decision-making algorithm is presented.

\section{Anatomy}

The elbow is a hinge joint that consists of three different bony articulations: the radiocapitellar joint, the ulnohumeral joint, and the proximal radioulnar joint, all of which are enclosed by a common synovial capsule $^{10}$. These bony elements provide stability at an elbow flexion angle of $<20^{\circ}$ or $>120^{\circ} 10,11$. The radiocapitellar joint resists compression at $90^{\circ}$ and inhibits posterior migration, while the ulnohumeral joint is the primary determinant of static and dynamic elbow stability. The proximal radioulnar joint has no effective role in elbow stability ${ }^{11}$. Osseous elbow structures 

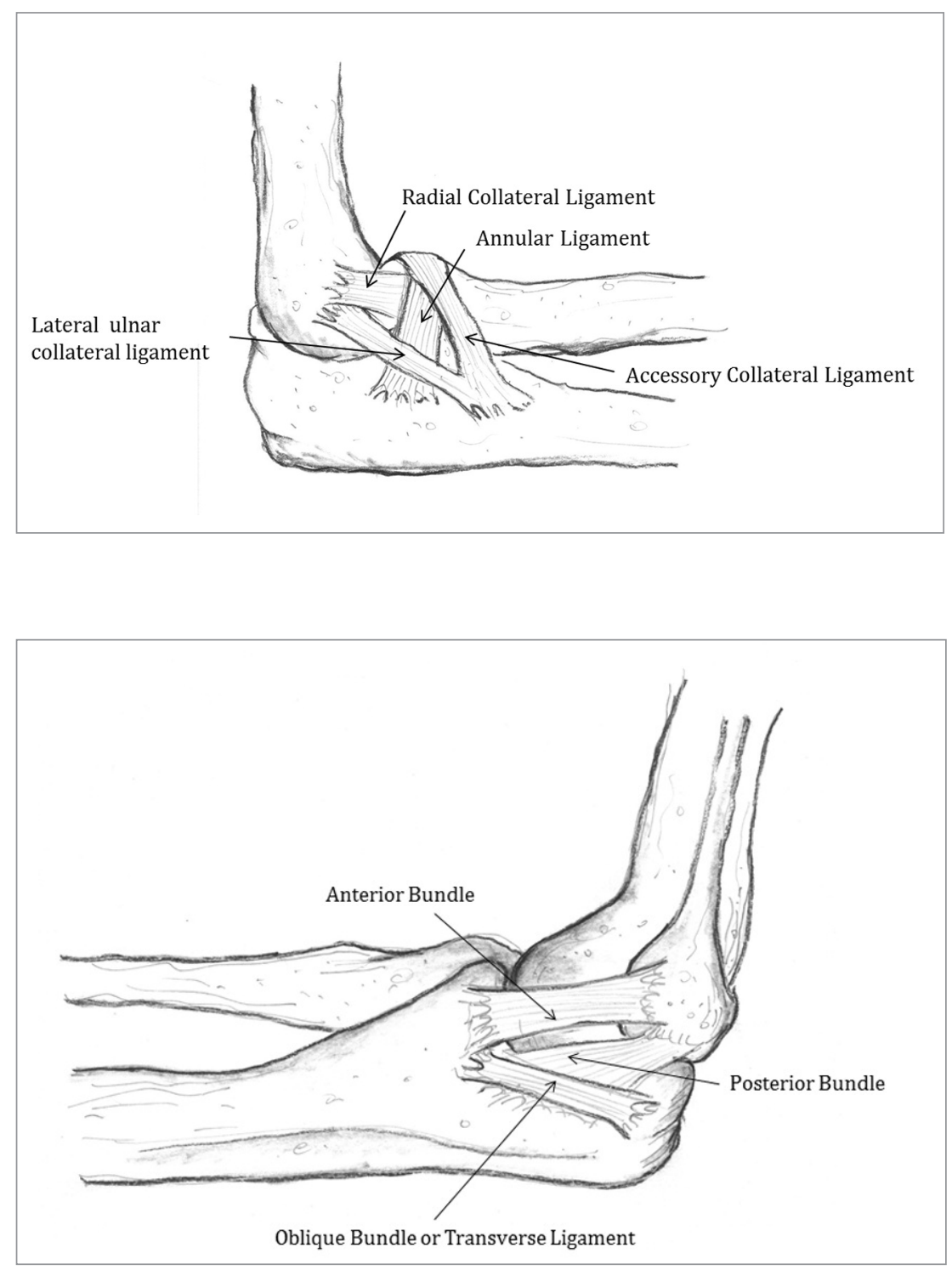

Figure 1. Lateral collateral ligament (LCL) complex.
Figure 2. Medial collateral ligament

(MCL) Complex. provide $50 \%$ of the overall stability (as a result of their primary role in resisting varus stress in elbow extension). Soft tissues including the anterior joint capsule, the MCL and the lateral collateral ligament (LCL) provide the remaining stability ${ }^{4,11}$.

Soft tissue elements provide primary non-contractile and contractile stability from $20^{\circ}$ to $120^{\circ}$ of elbow flexion, the range in which most overhead throwing occurs ${ }^{10,11}$. The LCL is composed of the lateral ulnar collateral ligament, the radial collateral ligament, the accessory collateral ligament, and the annular ligament (Fig. 1). The lateral ulnar collateral ligament provides primary resistance to postero-lateral elbow joint rotation. The radial collateral ligament provides secondary restraint to varus elbow movement, providing between $10-15 \%$ of resistance at extension and $90^{\circ}$ of flexion ${ }^{12,13}$.

The primary soft tissue elbow stabilization source for the throwing athlete is provided by the MCL (Fig. 2). At $90^{\circ}$ of elbow flexion, the MCL accounts for $55 \%$ of the stabilizing resistance to valgus stress and $78 \%$ of the resistance to varus stress ${ }^{13}$. The MCL is composed of three distinct parts: the anterior bundle, the posterior bundle, and the oblique bundle (transverse ligament). The anterior bundle originates on the medial epicondyle of the humerus and inserts on the medial aspect of the coronoid process ${ }^{10}$. The anterior bundle is further divided into distinct anterior and posterior bands. The anterior band is the primary restraint for valgus strain for elbow flexion up to $90^{\circ}$, and the secondary restraint for further flexion. Conversely, the posterior band is an important restraint to valgus strain at flexion angles $>60^{\circ}$, but is a secondary restraint at lesser angles ${ }^{12,14,15}$. When MCL injury occurs, the anterior bundle is most often involved as it is the primary restraint to the valgus stress experi- 


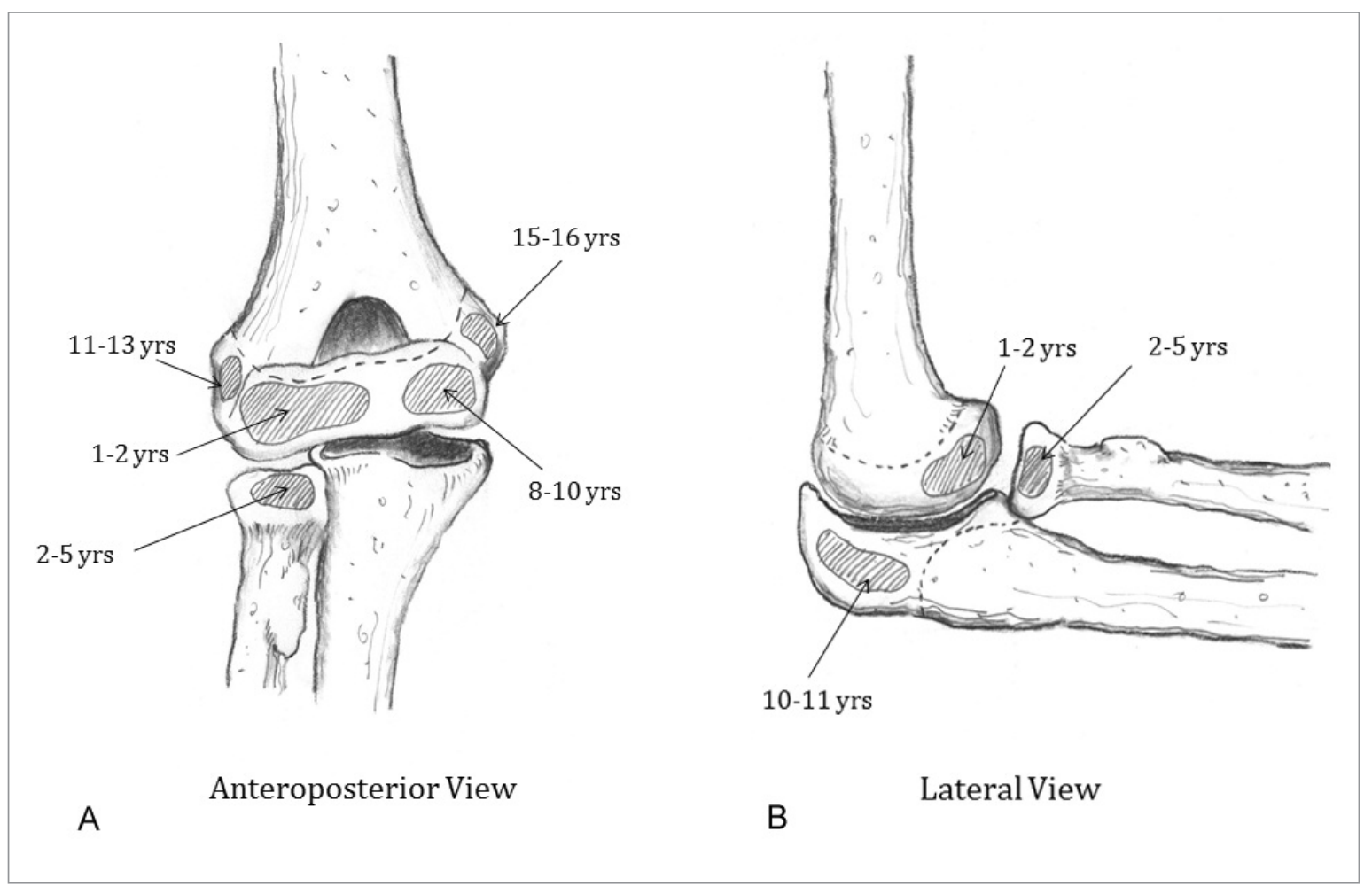

Figure 3. A) Elbow ossification centers and typical age of closure (Anteroposterior view) ${ }^{11,35}$. B) Elbow ossification centers and typical age of closure (Lateral view) ${ }^{11,35}$.

enced in the overhead thrower ${ }^{16}$. In cadaveric studies, the MCL has been directly measured to fail at between 22.7-33 Nm, while $120 \mathrm{Nm}$ of peak valgus torques have been measured at the medial elbow of experienced overhead throwers ${ }^{7,17-19}$. This discrephancy is explained by flexor-pronator musculature activation as a dynamic elbow joint stabilizer. The flexor-pronator musculature, which originates from the medial epicondyle and the distal medial epicondylar ridge of the humerus, helps to provide dynamic stability of the elbow against valgus stress ${ }^{10,12,14,15,20}$. The flexor-pronator musculature includes: pronator teres, flexor carpi radialis, palmaris longus, flexor digitorum superficialis, and flexor carpi ulnaris.

The posterior bundle of the MCL is fan-shaped, extending from the medial epicondyle of the humerus to attach to the medial margin of the semilunar notch of the ulna. Thinner and weaker than the anterior bundle, the posterior bundle provides secondary restraint to elbow valgus loads when elbow flexion is $>$ $90^{\circ 11,12}$. The posterior bundle is thought to be vulnerable to valgus overload strain only if the anterior bundle has been completely transected ${ }^{12,14}$. The oblique bundle plays no active role in elbow stability. Rather, it is a thickening of the joint capsule which travels between the medial olecranon and the inferior medial coronoid process ${ }^{12}$.

An important anatomic characteristic unique to the elbows of young athletes is the timeline of skeletal mat- uration. Six secondary ossification centers correspond to potential elbow injury sites (Figs. 3A and 3B), as the epiphyseal plates are believed to be $2-5$ times weaker than the surrounding osseous tissue, making them likely sites of overuse injury ${ }^{21,22}$. Fusion of the capitellum (1-2 years of age), radial head (2-5 years of age), elbow trochlea (8-10 years of age), olecranon process (10-11 years of age), and the lateral epicondyle (11-13 years of age) occur in a somewhat predictable, but variable manner. The medial epicondylar epiphysis (15-16 years of age) is the last ossification center to close. This is of particular importance to the overhead-throwing athlete ${ }^{15,23}$.

\section{Overhead Throwing Biomechanics}

Although shoulder kinematics and kinetics differ somewhat among various sports that require overhead throwing, the overall motions and forces that occur at the elbow joint are somewhat similar. Thus, the extensive studies that have been conducted regarding baseball pitching biomechanics can be extrapolated to other overhead throwing sports, particularly in regards to elbow function and stress ${ }^{24}$. The overhead throwing motion is composed of five main stages: Stage 1: the "windup" where the elbow is flexed and the glenohumeral joint is slightly internally rotated. Stage 2: "early cocking" which begins when the ball leaves the non-dominant hand and ends when the 
foot of the forward stride leg contacts the ground. During this stage, the glenohumeral joint begins to abduct and rotate externally. Stage 3: "late cocking" occurs as the glenohumeral joint goes into greater abduction and reaches maximal external rotation. During this stage the elbow flexes between $90-120^{\circ}$ and the forearm pronates $90^{\circ}$. Stage 4: "acceleration" occurs as the glenohumeral joint musculature and torque transferred from the lower extremity and trunk generate a large forward force on the upper extremity resulting in rapid glenohumeral joint internal rotationadduction, and elbow extension. This stage ends with ball release. Stage 5: "follow-through" represents deceleration during which all of the kinetic energy developed from the throwing motion is dissipated and upper extremity segmental movements rapidly decelerate ${ }^{12,15}$.

During the late cocking and acceleration phases of throwing the medial elbow is particularly prone to injury as tremendous valgus strain occurs. Maximum valgus stress reportedly occurs at $86^{\circ}$ of elbow flexion in adults and $87^{\circ}$ in adolescents, during the late cocking phase ${ }^{25}$. The maximum valgus torque in adolescent baseball players is $18-28 \mathrm{Nm}$, while that for professional baseball players may reach 90-120 $\mathrm{Nm}^{7,18,25}$. In addition to creating valgus elbow stress, the early and late cocking phases create compression forces at the lateral aspect of the radio capitellar joint. Late cocking can also create a shear force within the olecranon fossa of the humerus. The acceleration phase produces tension forces at the lateral ligaments and the lateral epicondyle of the humerus, contributing to lateral extension overload. Elbow extension velocity during the acceleration phase can reach $3000 \%$ s. The follow through phase creates hyper-extension stress in the anterior capsule of the elbow joint and the olecranon fossa ${ }^{23}$.

Several biomechanical factors have been correlated with increased elbow valgus torque in adolescent pitchers. Athlete height and bodyweight reportedly correlate most strongly with increased valgus torque. Both maximum gleno humeral joint abduction and internal rotation torque are negatively correlated with elbow valgus torque. Whereas, maximum gleno humeral joint external rotation and horizontal flexionextension torque are positively correlated with elbow valgus torque $7,25,26$. Huang et al. ${ }^{27}$ compared a group of 15 male subjects ( $11.3 \pm 0.6$ years of age) with medial elbow pain with an age- and gender-matched, healthy control group for baseball throwing kinematics. Compared to the control group subjects with medial elbow pain had reduced elbow flexion at maximum shoulder external rotation and had greater lateral trunk tilt at ball release. These subjects also displayed faster maximum upper torso rotational velocities, maximum pelvis rotation velocities and ball speeds. Maximum shoulder external rotation ( $r=$ $0.458, P=0.011$ ), elbow flexion angle at maximum shoulder external rotation $(r=-0.637, P=0.0003)$, and maximum upper torso rotation velocity $(r=0.562$, $\mathrm{P}=0.002)$ each displayed significant correlations with ball speed 27 .

\section{Injury Mechanism and Incidence}

Just as in professional pitchers, the valgus loads associated with overhead throwing in adolescent athletes can contribute to bony and capsuloligamentous elbow injuries. Little Leaguer's Elbow encompasses a group of injuries that occur from repetitive microtrauma at differing sites and structures within the immature elbow ${ }^{23}$. Medial elbow injuries that are considered components of the Little Leaguer's Elbow classification include: medial epicondyle injuries such as apophysitis, avulsion fracture, fragmentation, growth disturbance, delayed ossification, and accelerated growth; MCL injuries, common flexor tendon origin injuries, and ulnar neuritis ${ }^{23,28}$. Little Leaguer's Elbow is caused by valgus overload of the medial elbow structures, as repetitive flexor-pronator muscle activation regularly stresses the chondro-osseous origin causing apophyseal inflammation ${ }^{15}$. Increased resistance to valgus stress by the flexor-pronator musculature results in increased stress at the apophyseal insertion $^{21,29}$. As the apophysis is the weakest elbow structure in children, it is the site most vulnerable to injury in the growing elbow.

Although humeral medial epicondyle injuries typically occur from repetitive valgus forces, they can also result from acute trauma. Medial humeral epicondyle apophysitis is an injury of the skeletally immature child, caused by direct tractioning and marked by pain during the late cocking and early acceleration phases of throwing. Physical examination often reveals tenderness to direct palpation and swelling over the medial epicondyle of the humerus. Radiographs may reveal widening or abnormalities at the medial epicondyle ossification center ${ }^{30}$. In contrast, medial epicondyle avulsion generally affects more skeletally mature adolescents and results from either repeated micro trauma or acute elbow dislocation. On physical examination the clinician can appreciate loss of elbow motion and point tenderness over the medial epicondyle. Radiographs can demonstrate avulsion fractures with varying displacement ${ }^{23,30}$.

Following apophyseal ossification during adolescence there is a shift in the presentation of medial elbow injuries. Osbahr et al. ${ }^{31}$ evaluated 8 male baseball players, mean 13 years of age (range $=11-15$ years) with medial epicondyle avulsion fractures that occurred while throwing. All 8 subjects played multiple fielding positions, but pitcher was one of the primary positions they played. Seven of 8 players (87.5\%) were injured during one particular throw while pitching. One player was injured during a long throw from the outfield. Each player felt sudden pain or heard a "pop" while throwing. They also assessed subject adherence to the established recommendations of the USA Baseball Medical \& Safety Advisory Committee for 5 of the 8 players with this condition as they conformed to both the age (9-14 years old) and position (pitcher) requirements ${ }^{9}$. These 5 players did not adhere to the recommendations, including 2 players with high pitch counts, 2 players who pitched in multi- 
ple leagues, and 1 player who had multiple appearances in the same game. Among the 3 players who did not qualify for this assessment, two had pitch counts that exceeded the maximum number recommended for 13-15 year old players in one game (75 pitches/game). The final 15 year old pitcher threw fewer than 75 pitches but stayed in the game as an outfielder where he injured his elbow during a long throw late in the game ${ }^{31}$.

With maturation there is a shift from growth plate injuries to ligamentous injury, flexor-pronator musculature strain, and ulnar neuritis $23,32,33$. Medial elbow pain in overhead throwing athletes was first reported by Miller as "Javelin Thrower's Elbow"34. This microtrauma associated with repetitive valgus elbow stress can result in tissue attenuation and eventual ligament rupture ${ }^{10}$. Injury to the MCL can present as either a mid-substance, partial- or full-thickness tear ${ }^{35}$. Complete avulsions of the ulnar and humeral attachments of the anterior bundle of the MCL have are also reported $^{36}$. Concomitant ulnar nerve traction injury associated with valgus elbow instability has been reported in $40 \%$ of patients with a surgically repaired MCL ${ }^{16,30,37}$. Elbow injuries account for $9.3 \%$ of game injuries and $10.8 \%$ of practice injuries among NCAA baseball players ${ }^{38}$. Of the total of 836 elbow injuries reported, $593(70.9 \%)$ were associated with throwing. The highest percentage of elbow injuries associated with throwing occurred during pitching ( $n=465$, $78.4 \%$ ). Regardless if the elbow injury among NCAA baseball players was diagnosed as a ligament sprain (0.18 vs. 0.05$)$ or muscle-tendon strain (0.12 vs. $0.04)$ the injury rate/1000 exposures was at least three times as high during games as during practice $^{38}$. In a similar study that included a smaller subject sample, McFarland and Wasik ${ }^{39}$ reported that $12 \%$ of the total injury complaints among college baseball players were related to the elbow, and were responsible for $4 \%$ of all lost participation time. Although less common among NCAA softball players, elbow tendinitis during practice and elbow contusions during games occurred with an equal rate (each 0.04 injury rate/1000 exposures) ${ }^{40}$.

\section{Physical Examination and Diagnosis}

The evaluation and diagnosis of medial elbow injuries in the young athlete begins with comprehensive history-taking and physical examination. Age and skeletal maturation should be determined, as the injury profile changes with fusion of elbow region ossification centers. In questioning the athlete, it is important to determine whether the pain began acutely, or developed over time. This can help differentiate between overuse and acute injuries. The pathomechanical relationship of the pain the athlete experiences at different throwing motion phases is also important to determine, as different anatomical structures are stressed during each phase. Similarly, it is important to ask the athlete about recent performance reductions as chronic injuries may decrease strength, active mobility, and endurance. The athlete should also be cleared regarding the possibility of isolated or concurrent upper extremity neurovascular complaints, or possible ulnar nerve involvement. Among baseball pitchers, the clinician must inquire about additional risk factors that may increase the risk of elbow injury. These include involvement in multiple baseball leagues, throwing more than 80 pitches a month, participating in baseball more than 8 months during a given year, pitching at velocities $>85 \mathrm{mph}$, or use of curveball or slider pitches ${ }^{9}$. Prior treatment for any component of the whole body kinetic chain involved in overhead throwing should likewise be noted.

As with any focused physical examination, medial elbow examination begins with observation. The clinician should note evidence of ecchymosis, muscle atrophy, skin lesions, or an increased carrying angle $\left(>20^{\circ}\right)$. Observation of an increased carrying angle at the affected elbow can help identify a chronic pathology. The physical examination continues with elbow palpation to evaluate tenderness overlying the medial epicondyle of the humerus, medial epicondyle apophysis, or MCL. The clinician should also conduct an upper quarter screen to rule out neurovascular dysfunction at the cervical spine, thoracic outlet, elbow, or more distal upper extremity regions. This should include a cervical spine mobility scan, dermatome specific sensory and myotome specific strength assessments in the median, radial, ulnar and musculocutaneous nerve distributions (with special attention focused on the ulnar nerve), and deep tendon reflexes should also be performed. An upper quarter screen is particularly useful in athletes whose history suggests possible cervical spine involvement, referred pain, or when the symptom source based on history remains unclear. Finally active and passive shoulder, elbow, and wrist range of motion should be evaluated. These findings should be compared with the non-involved upper extremity and with dominant upper extremity normative values.

Elbow valgus stress testing can identify injury to the anterior band of the MCL. To perform this test the examiner applies a valgus stress to the elbow while it is flexed $25-30^{\circ}$. Alternatively, the "milking maneuver" can be performed to test the posterior band of the MCL. In this procedure, the examiner applies a downward, valgus torque when the forearm is supinated and the elbow is flexed $>90^{\circ} 12,15,37$. The "Moving Valgus Stress Test" has been shown to be $100 \%$ sensitive and $73 \%$ specific in identifying MCL injury, and is therefore preferred ${ }^{10}$. In this test, the examiner applies and sustains a constant valgus torque to the fully flexed elbow, which is quickly extended. If this movement reproduces medial elbow pain, the test is positive for MCL injury. Differentiation between an injured MCL and flexor-pronator muscle injury is verified by the absence of increased pain near the origin of the flexor-pronator musculature origin with wrist flexion $^{12}$. Eygendaal et al. ${ }^{41}$ reported that identification of isolated partial-thickness anterior bundle MCL 
tears based on medial joint opening and valgus laxity is impossible, although it can be used to diagnose full-thickness tears.

\section{Diagnostic Imaging}

Imaging studies can help confirm diagnoses based on physical examination information and aid in treatment planning. Both anterior-posterior and lateral radiographs should be obtained to rule out medial epicondyle avulsion fractures, as well as loose bodies, osteochondritis, bone spurs, and ligament calcification ${ }^{16}$. Since ossification centers remain open in young athletes, a lateral radiograph with the elbow flexed $90^{\circ}$ can reveal the radiocapitellar and ulnohumeral articulations, as well as the distal humerus, and identify apophyseal injuries ${ }^{4}$. Stress radiographs can also be obtained to confirm elbow valgus instability, with a joint opening $>3 \mathrm{~mm}$ indicating instability ${ }^{42,43}$. Using stress radiography, Ellenbecker et al. ${ }^{44}$ measured the joint space width between the trochlea of the humerus and coronoid process of the ulna of 40 healthy professional baseball pitchers. Results showed increased medial elbow laxity in the dominant arm of uninjured pitchers compared to their nondominant arm. Using MRI to evaluate 554 baseball players who were referred for shoulder and elbow rehabilitation Han et al. ${ }^{45}$ reported that junior high school players sustained a greater frequency of osteochondritis dissecans compared with high school and collegiate players. High school and collegiate players were more likely to have MCL injuries or superior labrum anterior-posterior lesions than junior high school players. Pitchers and outfielders were more likely to have MCL injuries than infielders. Among junior high players those with MCL injuries were taller and heavier 45 .

Magnetic resonance imaging (MRI) is also valuable in identifying athletes with MCL injury, as it has been shown to have $100 \%$ sensitivity and $100 \%$ specificity in identifying full-thickness tears ${ }^{35,46,47}$. MRI is also $100 \%$ specific in identifying partial-thickness $\mathrm{MCL}$ tears, although it is much less sensitive at $57 \%$. MRI arthography can also be used in cases where partial thickness tears are suspected $35,42,48$. Wei et al. 49 evaluated nine little league baseball players between 8-13 years of age that had a clinical diagnosis of Little Leaguer's Elbow. The primary or secondary position played by most subjects ( 8 of $9,88.9 \%$ ) was pitcher. Most players complied with pitch count recommendations. Four out of nine players however were throwing breaking pitches. Radiographic abnormalities were present in 6 players. All subjects displayed a normal MCL on MRI with no differences in distance between the MCL origin and the medial epicondyle physis noted between the injured and healthy elbows. MRI was found to demonstrate more abnormalities than simple radiographs; however the increased number of abnormal findings did not alter clinical management. MRI evaluation of the MCL demonstrated no role for surgical reconstruction in Little Leaguer's Elbow ${ }^{49}$. Given the close proximity of the MCL origin to the physis, any surgical procedure in this region should be a last resort and only performed with caution.

Dynamic ultrasonography is an effective tool for evaluating MCL injury; however it is somewhat operatordependent ${ }^{50}$. Computed tomography arthrography had been shown to be $86 \%$ sensitive and $91 \%$ specific for MCL injury diagnosis ${ }^{47}$. Sasaki et al. ${ }^{51}$ performed ultrasonography of the medial elbow of 30 healthy college baseball players while applying gravity stress at $90^{\circ}$ flexion. Medial elbow laxity and valgus on the throwing side was increased compared with non-players. In using fluroscans to compare 48 healthy overhead throwing sport athletes with 88 healthy non-overhead throwing sport athletes for acquired valgus elbow laxity, Singh et al. ${ }^{52}$ reported no group differences. This finding suggested that acquired valgus laxity was not evident in asymptomatic athletes.

\section{Conservative Treatment}

Conservative treatment for medial elbow injuries associated with throwing generally has positive results. Children who develop overuse elbow injuries are typically the best players, and usually are pitchers. Since these players are the ones that coaches desire to have on their team they require special protection in the form of enforced rest periods ${ }^{53}$. Among athletes with no radiographic or MRI evident changes, elbow and wrist muscle strengthening exercises may be beneficial, but the origin of the pain must be established. In athletes with osteochondritis or valgus overload syndrome, strict rest from compressive forces is recommended 53,54 . Two to eight weeks of rest coupled with judicious use of ice massage and nonsteroidal anti-inflammatory medication, and a supervised rehabilitation program focusing on restoring pain-free active elbow and wrist joint mobility, muscle strength and endurance are indicated ${ }^{12}$. Pain or antiinflammatory medications should never be used merely to enable the symptomatic athlete to continue sports activities. Corticosteroid injections are avoided, as they may further damage elbow ligamentous and cartilaginous structures. After 3-6 months of treatment, if symptoms have improved and the athlete has regained full range of motion and strength, a mediated throwing program may be initiated 53,54 . Most conservative treatment programs have shown full recovery rates of $40-50 \%$ in competitive overhead throwing athletes ${ }^{31}$. In non-throwing athletes results are better with full recovery in $100 \%$ of patients with MCL injuries treated conservatively ${ }^{24}$. We have summarized these findings into a medial elbow injury clinical management decision-making algorithm (Fig. 4). If conservative treatment fails referral to an orthopaedic surgeon is essential, as surgical intervention may be needed. There are several surgical techniques used to reconstruct the MCL. Reconstructive 


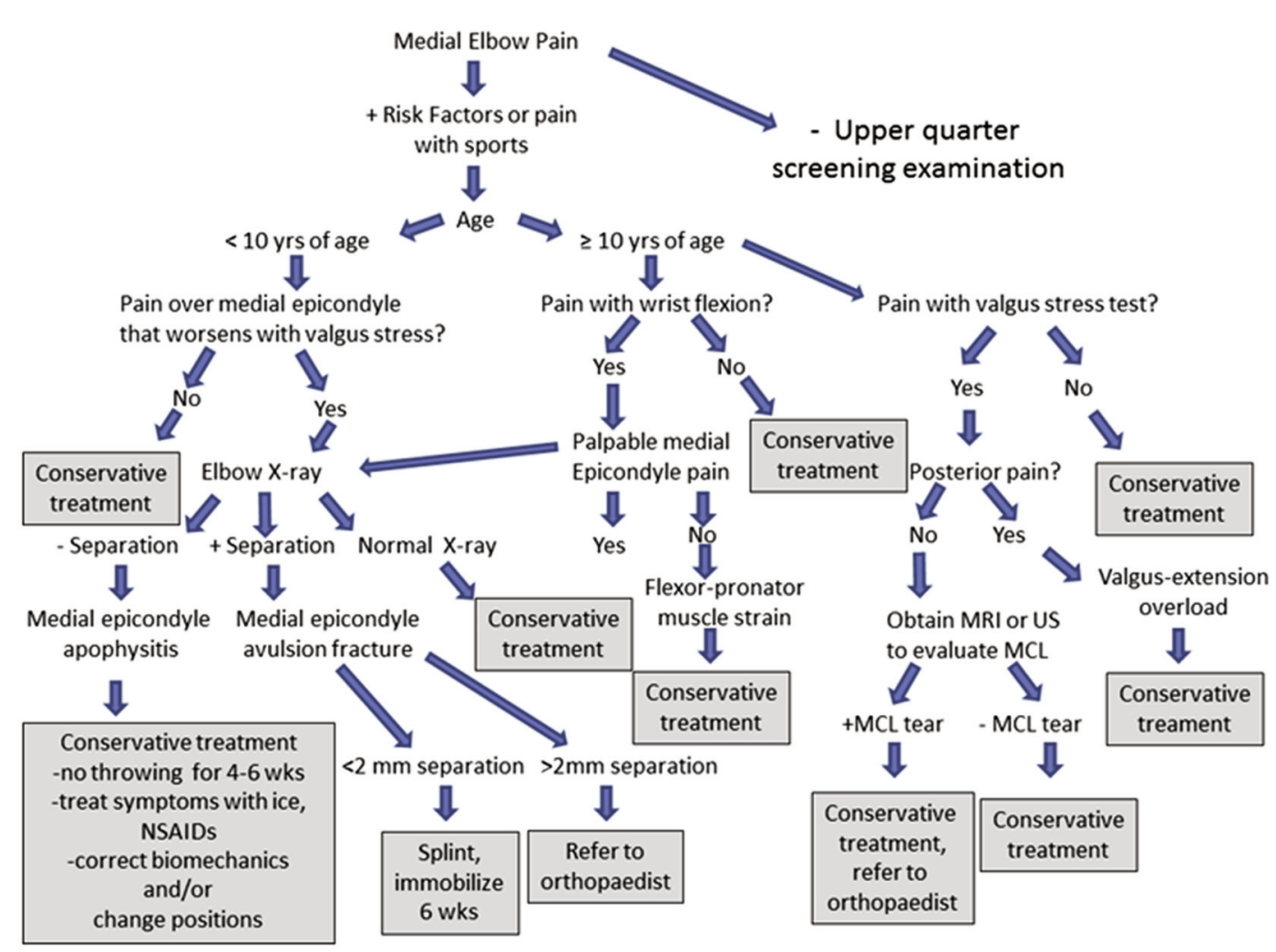

Figure 4. Medial elbow injury clinical management decision-making algorithm.

surgical approaches differ in terms of graft type, the number of strands, the placement and number of bone tunnels, and graft fixation ${ }^{55}$. All reconstruction techniques are favored over primary surgical repair of the native MCL because this has been shown to only yield a $50 \%$ return to previous level of activity ${ }^{37}$. The modified Jobe technique is considered a good surgical option with a $93 \%$ success rate in returning baseball pitchers to competition ${ }^{55,56}$. The docking technique, which has easier tunnel creation and graft passing, has also displayed a $92 \%$ success rate in returning baseball pitchers to competition ${ }^{19,55,57}$. Fixation using a hybrid interference screw has been shown in a cadaveric study to restore the MCL to $95 \%$ of its native valgus strength and within $<1 \%$ of native elbow valgus stability 55 .

\section{Conclusion}

Medial elbow overuse injuries are likely to occur with greater frequency as more adolescents become active in competitive sports, as the age at which they begin to specialize in one sport decreases, as the seasons become longer with multiple games and teams, and as the competitive level increases. The characteristics of these overuse injuries change as the bony elbow structure of the player reaches skeletal maturity, shifting from apophyseal injuries to midsubstance MCL injuries. Regardless of the specific tissue that is injured, all result from the high elbow joint loading volume (combined frequency, intensity) associated with throwing. Several overuse risk factors have been identified including heavy training loads, early sport-specific training, year-round throwing, participation in multiple sports, training errors, muscletendon strength and extensibility deficiencies, faulty equipment, and unqualified coaching or other supervisory practices ${ }^{58,59}$. Fleisig et al. ${ }^{18}$ used kinetic and kinematic analysis to evaluate 23 youth, 33 high school, 115 college, and 60 professional baseball pitchers. Kinetic differences observed suggested greater injury risk at higher competition levels. Greatest shoulder and elbow angular velocities were generated during arm cocking and acceleration phases. Pitchers need to learn proper mechanics as early as possible and develop neuromuscular strength proportionately as the body matures and as skill level continues to improve. Using similar biomechanical analysis methods, Davis et al. ${ }^{60}$ reported that youth pitchers with better pitching mechanics generated less shoulder internal rotation torque, less elbow valgus load, and more efficiency than those with improper mechanics. 
Table 1. USA Baseball Youth Baseball Pitching Recommendations ${ }^{9}$.

\begin{tabular}{|c|c|c|c|c|c|}
\hline Arm pain & \multicolumn{5}{|c|}{ Remove from game immediately; if $>4$ days of arm pain, seek medical attention } \\
\hline Pitch Counts & Game & Week & Season & Year & \\
\hline $9-10$ years old & 50 & 75 & 1000 & 2000 & \\
\hline 11-12 years old & 75 & 100 & 1000 & 3000 & \\
\hline 13-14 years old & 75 & 125 & 1000 & 3000 & \\
\hline Pitch Types & \multicolumn{5}{|c|}{ No breaking pitches until bones have matured around puberty ( $\sim 13$ years old) } \\
\hline Multiple Appearances & \multicolumn{5}{|c|}{ Once removed from the mound, do not return to pitching in the same game } \\
\hline Showcases & \multicolumn{5}{|c|}{$\begin{array}{l}\text { De-emphasize and/or avoid, if necessary; then give adequate time to prepare with no } \\
\text { overthrowing }\end{array}$} \\
\hline Multiple Leagues & \multicolumn{5}{|c|}{ Pitch for only 1 team at a time, with no overlapping seasons } \\
\hline Year-round Baseball & \multicolumn{5}{|c|}{ Baseball pitchers should compete in $<9$ months of baseball each year } \\
\hline
\end{tabular}

Table 2. Baseball pitcher minimum rest recommendations based on player age and the number of pitches thrown 62 .

\begin{tabular}{|c|c|c|c|c|}
\hline Age (years) & 1-Day Rest & 2-Day Rest & 3-Day Rest & 4-Day Rest \\
\hline $8-10$ & $21 \pm 18$ & $34 \pm 16$ & $43 \pm 16$ & $51 \pm 19$ \\
\hline $11-12$ & $27 \pm 20$ & $35 \pm 20$ & $55 \pm 23$ & $58 \pm 18$ \\
\hline $13-14$ & $30 \pm 22$ & $36 \pm 21$ & $56 \pm 20$ & $70 \pm 20$ \\
\hline $15-16$ & $25 \pm 20$ & $38 \pm 23$ & $62 \pm 23$ & $77 \pm 20$ \\
\hline $17-18$ & $27 \pm 22$ & $45 \pm 25$ & $62 \pm 21$ & $89 \pm 22$ \\
\hline
\end{tabular}

Increased pitch counts, early use of curveball or slider pitches, and year-round play have also been identified as medial elbow injury risk factors ${ }^{5,6}$. At the professional level the general belief is that 100-120 pitches thrown in competition during a 5-day period should be the maximum allowed for any pitcher ${ }^{53}$. In a 10 -year study, Fleisig et al. ${ }^{61}$ performed annual interviews of 481 youth pitchers (9-14 years of age). Injury was defined as elbow surgery, shoulder surgery, or withdrawal due to throwing injury. The cumulative injury incidence was $5 \%$. Participants who pitched $>$ 100 innings/year were 3.5 times more likely to be injured. Pitchers who played catcher as their secondary position seemed to be injured more frequently ${ }^{61}$. In a survey of baseball experts (orthopedists, surgeons, and coaches) regarding pitch limits, the consensus was that the number of pitches thrown was much more important than the number of innings pitched when determining rest requirements for young baseball pitchers ${ }^{62}$. Youth pitching and minimum rest recommendations are presented in Table $1^{9}$ and Table $2^{62}$, respectively.

Although baseball and other sports that induce valgus stress at the elbow such as javelin throwing rely on similar upper extremity motions, the frequency and variety of overuse injury varies in each sport. Among young javelin throwers, the most prevalent medial elbow injury occurs directly at the MCL. This difference is most likely related to the age at which each sport begins and participant age at the onset of competitive play. For example, in baseball the Little League World Series is held for athletes $\leq 13$ years of age, with children beginning competitive play many years earlier. In youth baseball players the most frequently reported medial elbow injury is "Little Leaguer's Elbow" which occurs in almost $25 \%$ of athletes ${ }^{5,6}$. In contrast, National-level javelin throwing competition does not begin until the high school years. Thus, the incidence and specific location of medial elbow overuse injuries with respect to overhead sports performance represents the interaction between the athletes' developmental status and the onset of high frequency or high intensity levels of competitive play.

\section{References}

1. Adirim TA,Cheng TL. Overview of injuries in the young athlete. Sports Med 2003; 33(1):75-81.

2. Difiori JP. Overuse injuries in children and adolescents. Phys Sportsmed 1999; 27(1):75-89.

3. Micheli LJ. Sports injuries in children and adolescents. Questions and controversies. Clin Sports Med 1995; 14(3):727-745.

4. Chen AL, Youm T, Ong BC, Rafii M, Rokito AS. Imaging of the elbow in the overhead throwing athlete.Am J Sports Med 2003; 31(3):466-473.

5. Lyman S, Fleisig GS, Andrews JR, Osinski ED. Effect of pitch 
type, pitch count, and pitching mechanics on risk of elbow and shoulder pain in youth baseball pitchers. Am J Sports Med 2002; 30(4):463-468.

6. Lyman S, Fleisig GS, Waterbor JW, Funkhouser EM, Pulley L, Andrews JR, Osinski ED, Roseman JM. Longitudinal study of elbow and shoulder pain in youth baseball pitchers. Med Sci Sports Exerc 2001; 33(11):1803-1810.

7. Werner SL, Murray TA, Hawkins RJ, Gill TJ. Relationship between throwing mechanics and elbow valgus in professional baseball pitchers. J Shoulder Elbow Surg 2002; 11(2):151155.

8. Ahmad CS, Grantham J,Greiwe RM. Public perceptions of Tommy John surgery. Phys Sportsmed 2012; 40(2):64-72.

9. USA Baseball Medical and Safety Advisory Committee Guidelines: May 2006. USA Baseball Medical \& Safety Advisory Committee. Youth baseball pitching injuries. http://web.usabaseball.com/.

10. Miller CD, Savoie 3rd FH. Valgus extension injuries of the elbow in the throwing Athlete. J Am Acad Orthop Surg 1994; 2(5):261-269.

11. Schwab SA.Epiphyseal injuries in the growing athlete. Can Med Assoc J 1977; 117(6):626-630.

12. Chen FS, Rokito AS, Jobe FW. Medial elbow problems in the overhead-throwing athlete. J Am Acad Orthop Surg 2001; 9(2):99-113.

13. Morrey BF, An KN. Articular and ligamentous contributions to the stability of the elbow joint. Am J Sports Med 1983; 11(5):315-319.

14. Callaway GH, Field LD, Deng XH, Torzilli PA, O’Brien SJ, Altchek DW, Warren RF. Biomechanical evaluation of the medial collateral ligament of the elbow. J Bone Joint Surg Am 1997; 79(8):1223-1231

15. Chen FS, Diaz VA, Loebenberg M, Rosen JE. Shoulder and elbow injuries in the skeletally immature athlete. J Am Acad Orthop Surg 2005; 13(3):172-185.

16. Field LD, Savoie FH. Common elbow injuries in sport. Sports Med 1998; 26(3):193-205.

17. Ahmad CS, Lee TQ, ElAttrache NS. Biomechanical evaluation of a new ulnar collateral ligament reconstruction technique with interference screw fixation. Am J Sports Med 2003; 31(3):332-337.

18 Fleisig GS, Barrentine SW, Zheng N, Escamilla RF, Andrews JR. Kinematic and kinetic comparison of baseball pitching among various levels of development. J Biomech 1999; 32(12):1371-1375.

19. Paletta GA Jr, Klepps SJ, Difelice GS, Allen T, Brodt MD, Burns ME, Silva MJ, Wright RW. Biomechanical evaluation of 2 techniques for ulnar collateral ligament reconstruction of the elbow. Am J Sports Med 2006; 34(10):1599-1603.

20. Davidson PA, Pink M, Perry J, Jobe FW. Functional anatomy of the flexor pronator muscle group in relation to the medial collateral ligament of the elbow. Am J Sports Med 1995; 23(2):245-250.

21. Godshall RW, Hansen CA. Traumatic ulnar neuropathy in adolescent baseball pitchers. J Bone Joint Surg Am 1971; 53(2):359-361.

22. Schwab GH, Bennett JB, Woods GW, Tullos HS. Biomechanics of elbow instability: the role of the medial collateral ligament. Clin Orthop Relat Res 1980(146):42-52.

23. Klingele KE, Kocher MS. Little league elbow: valgus overload injury in the paediatric athlete. Sports Med 2002; 32(15):1005-1015.

24. Jobe FW, Stark H, Lombardo SJ. Reconstruction of the ulnar collateral ligament in athletes. J Bone Joint Surg Am1986; 68(8):1158-1163.

25. Sabick MB, Torry MR, Lawton RL, Hawkins RJ. Valgus torque in youth baseball pitchers: A biomechanical study. J Shoulder Elbow Surg 2004; 13(3):349-355.
26. Hutchinson MR, Wynn S. Biomechanics and development of the elbow in the young throwing athlete. Clin Sports Med 2004; 23(4):531-544.

27. Huang YH, Wu TY, Learman KE, Tsai YS. A comparison of throwing kinematics between youth baseball players with and without history of medial elbow pain. Chin J Physio 2010; 53(3):160-166.

28. Gerbino PG.Elbow disorders in throwing athletes. Orthop Clin North Am 2003; 34(3):417-426.

29. Gore RM, Rogers LF, Bowerman J, Suker J, Compere CL. Osseous manifestations of elbow stress associated with sports activities. AJR Am J Roentgenol 1980; 134(5):971-977.

30. Greiwe RM, Saifi C, Ahmad CS. Pediatric sports elbow injuries. Clin Sports Med 2010; 29(4):677-703.

31. Osbahr DC, Chalmers PN, Frank JS, Williams RJ 3rd, Widmann RF, GreenDW. Acute, avulsion fractures of the medial epicondyle while throwing in youth baseball players: A variant of Little League elbow. J Shoulder Elbow Surg 2010; 19(7):951-957.

32. Kocher MS, Waters PM, Micheli LJ. Upper extremity injuries in the paediatric athlete. Sports Med 2000; 30(2):117-135.

33. Lin F, Kohli N, Perlmutter S, Lim D, Nuber GW, Makhsous M.Muscle contribution to elbow joint valgus stability. J Shoulder Elbow Surg 2007; 16(6):795-802.

34. Miller JE. Javelin Thrower's Elbow. J Bone Joint Surg Br 1960; 42:788-792.

35. Tuite MJ, Kijowski R.Sports-related injuries of the elbow: an approach to MRI interpretation. Clin Sports Med 2006 25(3):387-408.

36. Salvo JP, Rizio L 3rd, Zvijac JE, Uribe JW, Hechtman KS. Avulsion fracture of the ulnar sublime tubercle in overhead throwing athletes. Am J Sports Med 2002; 30(3):426-431.

37. Conway JE, Jobe FW, Glousman RE, Pink M.Medial instability of the elbow in throwing athletes. Treatment by repair or reconstruction of the ulnar collateral ligament. J Bone Joint Surg Am 1992; 74(1):67-83.

38. Dick R, Sauers EL, Agel J, Keuter G, Marshall SW, McCarty $\mathrm{K}, \mathrm{McF}$ arland $\mathrm{E}$. Descriptive epidemiology of collegiate men's baseball injuries: National Collegiate Athletic Association injury surveillance system, 1988-1989 through 2003-2004. J Athl Train 2007; 42(2):183-193.

39. McFarland EG, Wasik M. Epidemiology of collegiate baseball injuries. Clin J Sports Med 1998; 8:10-13.

40. Marshall SW, Hamstra-Wright KL, Dick R, Grove KA, Agel J. Descriptive epidemiology of collegiate women's softball injuries: National Collegiate Athletic Association injury surveillance system, 1988-1989 through 2003-2004. J Athl Train 2007; 42(2):286-294

41. Eygendaal D, Olsen BS, Jensen SL, Seki A, Sojbjerg JO Kinematics of partial and total ruptures of the medial collateral ligament of the elbow. J Shoulder Elbow Surg 1999; 8(6):612-616.

42. Emery $\mathrm{KH}$. Imaging of sports injuries of the upper extremity in children. Clin Sports Med 2006; 25(3):543-568.

43. Rijke AM, Goitz HT, McCue FC, Andrews JR, Berr SS. Stress radiography of the medial elbow ligaments. Radiol 1994; 191(1):213-216

44. Ellenbecker TS, Mattalino AJ, Elam EA, Caplinger RA. Medial elbow joint laxity in professional baseball pitchers. A bilateral comparison using stress radiography. Am J Sports Med 1998; 26(3):420-424.

45. Han KJ, Kim YK, Lim SK, Park JY, Oh KS. The effect of physical characteristics and field position on the shoulder and elbow injuries of 490 baseball players: Confirmation of diagnosis by magnetic resonance imaging. Clin J Sports Med 2009; 19(4):271-276.

46. Murphy BJ. MR imaging of the elbow. Radiol 1992; 184(2):525-529. 


\section{B. Gregory et al.}

47. Timmerman LA, Andrews JR. Undersurface tear of the ulnar collateral ligament in baseball players. A newly recognized lesion. Am J Sports Med 1994; 22(1):33-36.

48. Schwartz ML, al-Zahrani S, Morwessel RM, Andrews JR. UInar collateral ligament injury in the throwing athlete: evaluation with saline-enhanced MR arthrography. Radiol 1995; 197(1):297-299

49. Wei AS, Khana S, Limpisvasti O, Crues J, Podesta L, Yocum LA. Clinical and magnetic resonance imaging findings associated with little league elbow. J Pediatr Orthop 2010; 30(7):715-719.

50. Nazarian LN, McShane JM, Ciccotti MG, O'Kane PL, Harwood MI. Dynamic US of the anterior band of the ulnar collateral ligament of the elbow in asymptomatic major league baseball pitchers. Radiol 2003; 227(1):149-154.

51. Sasaki J, Takahara M, Ogion T, Kashiwa H, Ishigaki D, Kanauchi Y. Ultrasonographic assessment of the ulnar collateral ligament and medial elbow laxity in college baseball players. J Bone Joint Surg Am 2002; 84:525-531.

52. Singh H, Osbahr DC, Wickham MQ, Kirkendall DT, Speer KP. Valgus laxity of the ulnar collateral ligament of the elbow in collegiate athletes. Am J Sports Med 2001; 29(5):558-561.

53. McFarland EG, Ireland ML. Rehabilitation programs and prevention strategies in adolescent throwing athletes. Instruc Course Lect 2003; 52:37-42.

54. Axe MJ, Snyder-Mackler L, Konin JG, Strube MJ. Development of a distance-based interval throwing program for Little League-aged athletes. Am J Sports Med 1996; 24:594-602.
55. Ahmad CS, ElAttrache NS. Elbow valgus instability in the throwing athlete. J Am Acad Orthop Surg 2006; 14(12):693700 .

56. Thompson WH, Jobe FW, Yocum LA, Pink MM.Ulnar collateral ligament reconstruction in athletes: muscle-splitting approach without transposition of the ulnar nerve. J Shoulder Elbow Surg 2001; 10(2):152-157.

57. Rohrbough JT, Altchek DW, Hyman J, Williams RJ 3rd, Botts JD. Medial collateral ligament reconstruction of the elbow using the docking technique. Am J Sports Med 2002; 30(4):541-548.

58. Caine D, Maffulli N, Caine C. Epidemiology of injury in child and adolescent sports: injury rates, risk factors, and prevention. Clin Sports Med 2008; 27(1):19-50.

59. Demorest RA, Landry GL. Prevention of pediatric sports injuries. Curr Sports Med Rep 2003; 2(6):337-343.

60. Davis JT, Limpisvasti O, Fluhme D, Mohr KJ, Yocum LA, Elattrache NS, Jobe FW. The effect of pitching biomechanics on the upper extremity in youth and adolescent baseball pitchers. Am J Sports Med 2009; 37(8):1484-1491.

61. Fleisig GS, Andrews JR, Cutter GR, Weber A, Loftice J, McMichael C, Hassell N, Lyman S. Risk of serious injury for young baseball pitchers: a 10-year prospective study. Am J Sports Med 2011; 39(2):253-257.

62. Andrews JR, Fleisig G. Medical and Safety Advisory Committee Special Report: How many pitches should I allow my child to throw? USA Baseball News, 1996. 